\title{
STATE AND PROBLEMS OF WAREHOUSING OF BULGARIAN ARMY
}

\author{
Vanya BANABAKOVA*, Stefan FILIPOV*, Stanimir STOYANOV** \\ *"Vasil Levski" National Military University, Veliko Tarnovo, Bulgaria \\ **Regional Office "Military police", Pleven, Bulgaria \\ v.banabakova@abv.bg, stefan_filip@abv.bg, stanimir_0606@abv.bg
}

\begin{abstract}
Storing material resources is a back-up function of military logistics, but its proper organization and successful improvement is a guarantee for effective and efficient realization of the whole logistics support process. For this reason it is advisable to elaborate the whole warehousing process in the Bulgarian Army (BA). The aim of this study is to analyze the state and problems of logistics and warehousing in the Bulgarian Army.
\end{abstract}

Key words: logistics, logistic system, warehousing

\section{Introduction}

Dynamic changes in the socio-economic environment put the modern organizations in front of the variety of challenges in response of the need for their adaptability by increasing organizational flexibility, improvement and development of management tools.[1]

The new missions and tasks, BA living environment and the military-political reality in the world necessitated the inauguration of a transformation process of the organizational structure, functional relationships and administrative practice in the Ministry of Defence, Defence Headquarters of the Bulgarian Army. The aim of this transformation is to build up modern, usable and effective armed forces.

A new approach is necessary as to realize the principles of compatibility, usability, modularity, functionality and expeditiousness. The main efforts should be directed towards reaching multifunctionality in order to increase the operational effect and to reduce expenditures for staff, infrastructure, fighting equipment and battle training. [2]
The development of effective capacity requires permanent transformation, based on the lessons from participation in operations and missions, flexibility in conception development, effective military and logistics support, capacity for deployment and independent task fulfillment for a long period of time. [3]

Storing material resources is a back-up function of the military logistics, but its proper organization and successful improvement is a guarantee for effective and efficient realization of the whole logistics support process. [4]

Storing material resources for the Bulgarian Army is considered at two levels:

- First level - organizational and management structure of BA warehousing

- Second level - state of BA warehouses and organization of warehousing activities there.

For the purpose of this study the second level is analyzed.

The aim of this study is to analyze the state and problems of logistics and warehousing in the Bulgarian Army. 


\section{Role of warehousing as an element of BA logistic system.}

Currently, many warehouses at the various command levels are not necessary due to decrease in stock volume. This leads to significant staff reduction as a result of the elimination of military units and staff changes in warehouse structures, but at the same time staff duties are not reduced. The objective reality at the moment shows that warehousing activities are carried out through tolerating many and considerable omissions or compromises. [5]

For this reason it is advisable to improve the whole warehousing process in the Bulgarian Army.

Contemporary conceptions for warehousing exceed its four main operations - receiving, storing, selection and transportation and include many other additional services such as packaging, repairs of defence products, consolidating shipments, etc.

Within this point of view, a new different vision of warehousing should be built up. The view of warehousing should be - to think about warehousing as input-output valve that controls the influx and flow of defence products between production and consumption functions of BA logistic system. For reaching this purpose it is necessary to analyze the logistics and warehousing of the Bulgarian Army in contemporary conditions.

\section{Analysis of logistics and warehousing of the Bulgarian Army in contemporary conditions.}

The Ministry of Defence manages and coordinates the activity of logistics support of the armed forces. In cooperation with the other ministries and administrations, it develops and presents for confirmation to the higher defence management authorities plans for due provisioning and use of military and civil resources in operations at time of crisis, conflicts and war. Special attention is given to national resources, development of transport, infrastructure and industry as well as the activities related to force deployment and support by the hosting country. Determining and guaranteeing war-time needs of basic military and civil products and services for the armed forces is one of the main tasks of the logistics support system in peacetime. Resource provisioning of the defence requires not only producing and storing the necessary stock of material resources, but also guaranteeing the necessary services.[6] An integrated system for logistics support management is built up that consists of organizational structure (staff, equipment, installations), doctrines, procedures and communication and information technologies. This system provides due and expedient information for planning, management and control of the activities within all structures and levels. [7]

The functions, competencies and responsibilities in the sphere of logistics at the Ministry of Defence are related to: planning and realizing material resources acquisition from local producers and via import, codification, standardization, relations with national and international bodies, organizations in the sphere of logistics and creating organization for effective and efficient logistics support of the armed forces.

The main body for logistics support management at strategical level is Directorate "Logistics" at the Defence Headquarters.

BA logistics support management at operational level is fulfilled by "Logistics" departments, by the Joint Forces Command of the separate armed forces (Armed Forces, Air Forces and Maritime Forces), and at tactical level by "Logistics" Departments at the bases and brigades and by "Logistics" sections at the battalions.

Storing should guarantee stocks preservation in suitable conditions and ready to use. Security and safety requirements should be strictly observed in storing.

"Logistics" Brigade is a tactical military unit but fulfills functions at operational 
level regarding storing operational stocks of armaments, technics and material resources for the BA, as well repairing the technics of the JFC subordinate military units. It is deployed throughout the whole national territory and it provides material resources of all classes for all types of armed forces (AF) in peacetime. Completed with servicemen and civil servants at $94 \%$, it is able to fulfill the assigned tasks regardinglogistics support of the Bulgarian Army units in the country and contingents of foreign missions. [8]

"Logistics" Brigade has 28 subordinate military units, dislocated throughout the whole country.

The military unit in the village of Negushevo, region Sofia is a center for logistics support and is also called Central Supply Base - CSB, which is established on the grounds of Ministerail Order No OX-0020/17.08.2000, since 01.09.2000.

In organizational aspect the CSB is directly subordinate to "Logistics" Brigade and the performed tasks are related to the requirements of the Doctrine for Bulgarian Army Logistics and Conception for United Material and Technical Supply.

In the Central Supply Base and its subordinate sections are stored and handled material resources of classes - I, II, IV and part of class V, without class III (fuels, oils, greases). In organizational aspect the center consists of management, stationary warehouses for material resources (autoarmored, signaling, chemical, foodstuffs, object safekeeping and medical) and logistic-support company. In the CSB village of Negushevo stationary warehouses with their subordinate sections are deployed.

For fulfilment of logistic operations CSB Negushevo has at its disposal a logisticprovisioning company with three squads transport, repair and housekeeping.

It should be emphasized that the SCB takes a particularly important place within the general scheme of BA logistics support. It is a supply body of "Logistics" Brigade and its main task is to provide BA subdivisions with all types of material resources. The CSB is an independent military unit with a specific organizational and staff structure that allows successful completion of tasks assigned to the military forces, namely total, due and quality provisioning of BA units.

There are two Regional bases for supplying with logistic property directly subordinate to the Central Supply Base which are called Regional Supply Bases (RSB) situated in the city of Plovdiv and the village of Radko Dimitrievo - Shumen region, namely:

- In the city of Plovdiv - First Regional Base for storing logistic property and control on foods, installations and vehicles of high danger.

- In the village of Radko Dimitrievo, Shumen region - Second Regional Base for storing logistic property and control on foods, installations and vehicles of high danger.

RSBs are main units of the BA responsible for logistics support, which includes: supply and services for the BA staff; analysis, planning, spedition, delivery, storing, placement, transportation, distribution, technical support, evacuation, transfer, report and accounting of armament, machinery and other material resources; maintenance, exploitation and repairing of infrastructure. [9]

\section{State Analysis of the Central Supply Base, Regional Supply Bases and other warehouses of the Bulgarian Army.}

For analyzing the current state of warehousing in the Bulgarian Army a survey was conducted among the officers, sergeants and civil staff employed in the CSB - village of Negushevo and in the RSBs - village of Radko Dimitrievo and city of Plovdiv, as well the warehouses for storing motor vehicles - village of Resen and for armament - village of Dalga laka. The survey was held in the period 20122016. The specific method for warehousing examination is based on Bolton's system 
for evaluation and quality of warehousing services. [10]

Survey questions are grouped into 9 sections. Sections include the following main topics of research: state of the warehouse buildings and fields, equipment safety and security, sanitary conditions and buildings maintenance, servicing RSBs and the units situated in the responsibility zone, warehouse staff, warehouse operations on acceptance and dispatch of material resources, losses/damages of material resources, accountability and annual inventory.

The survey was held in all the analyzed warehouses and the participants were selected according to their job positions and are competent on the researched questions. On every line of the questionnaire sheet interviewees are required to fill in their evaluation on the respective element of warehousing activity with values from 1 to 5, which correspond as follows: 5 excellent mark for the state of the researched question; 4 - good mark for the state of the researched question; 3 -average mark for the state of the researched question; 2 - under the average mark for the state of the researched question; 1 - poor mark for the state of the researched question.

Based on the survey results the state and problems of BA warehousing could be outlined in the following directions:

\section{State analysis of buildings and fields}

Despite being built many years ago, buildings and fields in the monitored sites are in good condition. In Negushevo and Radko Dimitrievo warehouse buildings need renovation of exterior and repair of roof constructions. However, major repair costs would be necessary which cannot be currently afforded and chief officers are forced to undertake temporary solutions for mitigating the problems.

Parking lots and roads are in good condition excluding RSB - Plovdiv, where roads are narrow and it is difficult to manoeuvre.
Although in the CSB, RSB - Radko Dimitrievo and Resen bases there are conditions for using railway transport, it is not used. According to the contracts with delivery companies material resources are delivered vie motor transport to CSB or RSB. At present, railway transport is used as a transportation method only in the warehouse base Dalga Laka.

There are many ways for improving the supply of warehouse bases through various cargo vehicles. Head officers state that it is better economically grounded to use small cargo vehicles - mini-busses with bigger range, lower loading capacity and lower operating costs as well.

\section{Analysis of equipment safety and security}

The main problems found in the analysis of equipment safety and security are related to the lack of modern tools for monitoring and fire extinguishing/sprinkle system and smoke detectors/. Indeed, the existing fire equipment and tools are ready-to-use. In warehouse bases there are fire equipment and tools next to every storage building able to carry and transport fireextinguishers, trench instrument, pumps, etc. Fire-extinguishers are accessible and correctly situated to be easily found in case of need. They are kept in good working condition and are periodically checked-up at an authorized service-station where the relevant certificate is issued.

In warehouse bases there is an estimate of the fire-fighting forces and means - on-call fire-fighting body. Officers on duty are aware of the communication procedure with the police or fire brigade. In warehouse base - Radko Dimitrievo are held coordinated joint trainings with the Fire Authorities.

Fire safety in warehouse bases is subject to periodical unexpected inspections by the Military Police and "Logistics" Brigade special bodies. The assessments of the latest inspections in the monitored warehouse bases are "Excellent". 
The level of fire safety is maintained also with frequent instructions of the warehouses staff, the presence of fire safety instructions in every warehouse and office, and putting well-visible "No smoking" signs.

\section{Analyses of sanitary conditions and buildings maintenance}

In the analyses of this element there are very good assessments regarding building exterior, imposing regulations, control on warehouse pests, state of the systems for material resources storage, and warehouses internal marking. The activities for pests control are organized according to a plan together with the medical authorities in the warehouse base.

There could be found warehouse weaknesses related to the condition of the roof and interior lightening in the storage buildings just as in the initial stages of the examination.

Another aspect of storage buildings condition is ventilation. All the examined warehouses rely on natural ventilation - air ventilation of the premises with a view to regulate temperature and air humidity with regard to the measured levels in warehouses and climate characteristics of the season. Due to winter conditions during the examination period in the city of Plovdiv and the village of Resen, there are lower assessments. As a whole, because of the high temperature tolerance of the stored resources, the natural ventilation system totally covers storage requirements. However, this system cannot cover the need of creating optimal working conditions for the staff. In none of the examined warehouses is a heating system used, as a result in winter conditions the working environment is with temperature of 0 degrees Celsius.

One of the most important resources in every logistic system is the staff. The efforts for keeping their health safety and establishing safe working conditions is a high-priority task for every warehouse director. During the examination significant differences were noticed regarding the availability and use of safety equipment in the warehouses for object safekeeping and the other examined warehouses for storing motor vehicles and artillery weapons Figure 1.

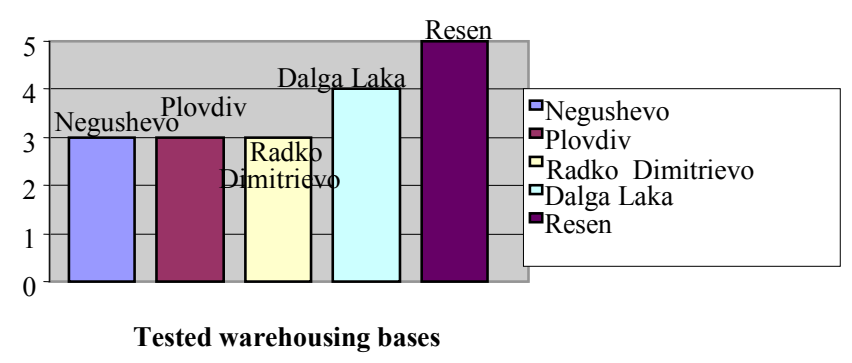

Figure 1. Availability of safety equipment for the staff

In the warehouses in Resen and Veliko Tarnovo /Dalga laka/ safety equipment for the staff is available and it is used in warehousing activities. Shoes with metal toe-caps, protective overalls, gloves, glasses, helmets, etc. are used.

\section{Warehouse staff analyses}

The survey shows that warehouse staff is controlled and supported by the management in doing warehousing activities. A committee of qualified persons is established when safekeeping objects clothes, shoes, etc. are accepted in RSB and CSB, who verify supply quantity and quality on the spot.

The limited number of warehouse staff provides for better management control. In the time when workers are not directly occupied with their main warehouse duties they fulfill other tasks as well, such as cleaning and maintenance of outside 
regions, construction and repair activities, etc.

\section{Analysis of warehousing activities - acceptance and dispatch of material resources}

Acceptance of material resources /goods/ in the examined warehouses is done with a view to check their quantity and quality and their compliance with the signed delivery contracts. For the acceptance of newly arrived material stocks from civil firms a committee is established which includes people acquainted with the specific features of different resources - representatives of the warehouse bases /including the head store/. When the quality of safekeeping objects is accepted, it is compared to the available specimen of the same goods.

It could be concluded that there are good relations with suppliers. Usually, material resources are dispatched with transport owned by the supplier and this helps to avoid controversies about protecting material resources during transportation. There are cases of refusal to accept the material which usually happen when the delivery arrives at non-working hours.

\section{Accountability analysis}

Accountability in the examined warehouses is at good level. This is due to the good training of the heads of store and servants. The main aspect that should be currently improved is providing real-time information /through establishing Information Logistics System/ and relating accountability with the exact place for storing materials in the storage space - the so called storage lots.

Despite the lack of modern information system the warehouse staff cope well with the selection process /Figure 2/. Thanks to their experience and knowledge of the materials they could easily find the material - subject to selection, re-arrangement, service and other warehousing activities.

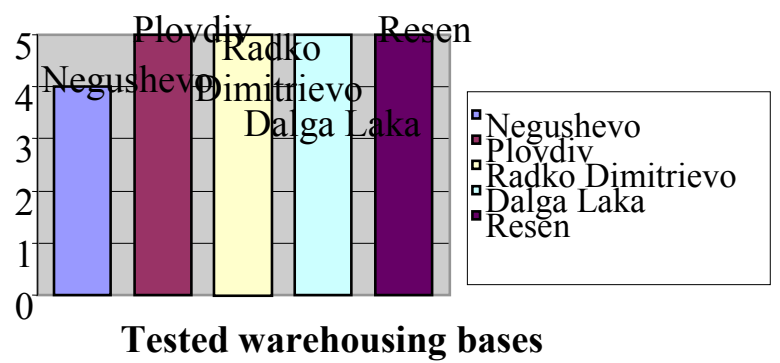

Figure 2. Finding stocks in the warehouse

As a result of the survey, a lot of important aspects of BA warehousing were examined. The state of warehouse buildings and fields, equipment safety and security, sanitary conditions and building maintenance, servicing of RSBs and the units in the responsibility area, warehouse staff, warehousing activities of material resources acceptance and dispatch, loss/damages of material resources, and state of accountability were examined.

The analysis of the examined warehousing activity elements requires purposeful work and efforts in the following directions:

- Investments in buildings maintenance and lightening are necessary, as well as purchasing modern transport means corresponding to the contemporary features of material flow in the logistic system;

- In warehouse bases for storing material property could be applied good practices used in the warehouses for storing motor vehicles and armament regarding maximum utilization of storage space and the broad use of stands as a universal system for storing material resources;

- Despite the staff good professional skills, more attention should be paid to their safety and security and providing good working conditions. In the warehouses for storing material property it would be purposeful to develop procedures for the use of safety technics and equipment in doing warehousing activities. 
- In the conditions of contemporary tasks and challenges faced by the logistics support and in particular - Bulgarian Army warehousing, the following conclusions could be drawn:

- Historically, warehousing has been an important element of the Bulgarian Army logistic system and has developed dynamically during the years. There are two main challenges standing in front of warehousing - creating stocks that could completely satisfy military needs of material resources and reaching higher effectiveness of the warehousing function.

- Higher level of warehousing could be achieved only through constant monitoring of the warehousing activities state and searching for ways of improvement. It is important to involve in the current analysis the warehouses directors and staff as they are well acquainted with the strengths and weaknesses of the offered logistic service. The applied approach should be pointed at investing in fields of warehousing that are lagging far behind world practices and threaten the fulfillment of the main warehouse functions, such fields are: investments in building maintenance, investments in modern information and communication systems, investments in safety and improving working conditions in the warehouses.

- One way to achieve maximum effect in logistics is to create and use modern information systems. Only generating and providing accurate information in real time would allow directors to take the most appropriate managerial decisions. Through using modern information systems for logistics management we would be able to use defence resources effectively and economically. The information system "BA Logistics" is an example for the ambition to reach this aim and its full implementation in all units of the Bulgarian Army will show the whole set of advantages that it provides.

In conclusion, regarding the new tasks given to the Bulgarian army, the logistics support system, and warehousing in particular, should create and provide a broad set of logistic services in the country and also for foreign operations and missions fulfillment. Foreign experience and the advantages of NATO, UN and EU membership should be utilized. At the same time, it should be agreed that operations supply would largely depend on the specific conditions of environment and on this grounds should be found flexible approaches and solutions for every single case.

[1] Dimitrova S., Nichev, N., Stefanov, N., Development of Outsourcing Services. International conference Knowledge-Based Organization, Volume 21, Issue 1, Pages 192-197, 2015.

[2] Report: "State and Tendencies for Development of BA Logistic System”, BA HQ, Sofia, 2007, p. 3.

[3] Report: "State and Tendencies for Development of BA Logistic System”, BA HQ, Sofia, 2007, p. 4.

[4] Ivanov, Iv. Guidelines for Improvement of BA Warehousing Activity, Year-book of Military Academy “G. S. Rakovski”, Command and Staff Faculty, S., 2006, p. 253.

[5] Ivanov, Iv. Guidelines for Improvement of BA Warehousing Activity, Year-book of Military Academy “G. S. Rakovski”, Command and Staff Faculty, S., 2006, p. 254.

[6] Doctrine for BA Logistics, S., 2013.

[7] Guidelines for Storing Property, Materials and Technics in BA Object Safekeeping Warehouses, Sofia, 1997, p. 15

[8] Report of the "Logistics" Brigade Commander, S. 2015.

[9] Report of RSB Chief, S. 2015.

[10] Bolten, E., Managing Time and Space in the Modern Warehouse, Amacom, 1997, p. 53. 